\title{
QUESTION
}

"What does economic anthropology contribute to the understanding of climate change?”

\author{
T. A. Reuter: Climate Change as a Cultural Artifact \\ SYMPOSIUM ESSAY
}

\section{Climate change as a cultural artifact: Anthropological insights to help avert systemic collapse}

Thomas A. Reuter

Asia Institute, The University of Melbourne, Parkville VIC 3010, Australia

Corresponding author: Thomas A. Reuter; e-mail: thor2525@gmail.com

Global warming has emerged as a menacing and time-sensitive systemic issue, and a paradigm shift in our thinking about the place of economics in human societies is urgently needed if we are to avert an environmental crisis of epic proportions this century. Anthropology, I shall argue, can get to the heart of this crisis by exposing false, pseudo-intellectual premises about nature (including human nature) within the pseudo-realist neoliberal ideology that upholds today’s dominant and highly destructive economic regime. Moreover, anthropology can help to

This is the author manuscript accepted for publication and has undergone full peer review but has not been through the copyediting, typesetting, pagination and proofreading process, which may lead to differences between this version and the Version of Record. Please cite this article as doi: $10.1002 /$ sea2.12197

This article is protected by copyright. All rights reserved. 
empirically document other, more life-affirming and sustainable economic orders through a comparative study of "human ecologies” (Reuter 2015a).

The designation “ecologies” herein refers to the historically dynamic sociocultural systems people have developed to manage their ecological interdependence with other life-forms within the shared context of the dynamic physical systems of nature. More narrowly conceived terms, such as "political ecology," in my opinion, do not sufficiently recognize the fact that all domains of human activity have implications for ecology, not just politics and economics. ${ }^{1}$

Comparative anthropology is able to map and critically evaluate the vast diversity of locality-specific human ecologies as well as identify common features of the most sustainable ecologies. A review of this growing field of research is beyond the scope of this essay. I will briefly summarize the main findings below, however. Together with a more ecological reading of evolutionary theory, this cross-cultural evidence serves as a counterargument to neoliberal ideology, which insists that rapacious human behavior under late capitalist conditions is “natural.” Instead, I argue that ecologies are cultural artifacts. As a general theoretical frame of reference, I will extend the well-established theory of “moral economies” to encompass the idea of moral ecologies.

\section{Insights from comparative studies of human ecologies across the course of evolution and across cultures}


Life is sustained by an unimaginably complex web of interdependence relationships among diverse species, humans included, as well as interactions between ecosystems and the physical systems of planet Earth. From the relative perspective of a species or individual, however, the degree of "interactive proximity" within an ecosystem varies. Symbiotic species are of course more intensely interdependent than species living on different continents, and individuals of the same life-form are even more intensely interdependent (reproduction, parental care, etc.). Interdependence is greatest, however, among individuals of a species that is reliant on differentiated social systems. Humans are the most mutually interdependent or "social" of all life-forms.

For humans, social systems are the "near-end" of an encompassing planetary system of ecological interdependencies. Key ecological imperatives, such as diversification and mutual interdependence, thus apply equally to the "social" world as they do to the "natural" world. The underlying unity of natural and social systems also explains why ecologically destructive economic regimes tend to be socially destructive as well (Gould, Pellow, and Schnaiberg 2004).

The spectacular evolutionary success of the human species is based on our ability to differentiate and cooperate socially on an unprecedented scale, facilitated by our endowment for language-based communication and social diversification. In human societies, the evolutionary drive toward diversification and systemic interdependence acquires a new, sociocultural expression. Specifically, in economics, it takes the form of a division of labor based on differentiation of acquired knowledge and skills. Early social scientists like Durkheim and 
Weber already noted the importance of labor division for cultural evolution. Historical research by Norbert Elias (1982) further shows that the rise of ever more complex webs of interdependence within ever more diverse social systems has been a fairly consistent trend and the driving force of civilization.

Why, then, is our current economic regime so destructive, disrupting the entire biosphere and even the planet's geophysical systems and climate? It seems we have forgotten the far end of the planetary system of mutual interdependence, including the nonhuman world but also disadvantaged members of our own, human family. Is such predatory self-serving behavior a distinctive feature of human nature and thus inevitable? Is climate change a natural consequence of our cultural evolution?

Clearly not. Anthropogenic climate change may be a major feature of the Anthropocene, the "geological age that man created" (Crutzen and Stoermer 2000, 17). The forces that initiated this era do not stem from our intrinsic nature, however, since this era did not commence with the emergence of Homo sapiens. Rather, people have lived relatively sustainably since modern humans first evolved some 195,000-160,000 years ago. The current crisis originated in the age of industrialization and only began to accelerate exponentially in the post-World War II period of rampant consumer capitalism. Moreover, what is true across temporal scales is true also across geographical regions: The vast majority of non-Western societies studied by anthropologists appear to have lived relatively sustainably until recently, and many continue to do so, as indeed 
Western societies did prior to the Industrial Revolution. Sustainability has been the rule rather than the exception.

Anthropologists have also documented that many indigenous societies heed their moral relationship to nature and to one another. Not only are they very community minded but they also consider other species as agents with distinctive subject positions or "perspectives” (Viveiros de Castro 2004) and view nature as an intrinsically social world of interdependencies in which humans are embedded (Descola 2005). In short, climate change is not happening because of some intrinsic element of human nature; it is a cultural artifact.

What, then, is the precise cultural complex that has turned us into a system-threatening, disruptive species? The extensive data set of the Global Footprint Network (2011) plainly shows that an extremely heavy ecological footprint correlates closely with a high degree of Westernstyle, modernist development. Today’s dominant economic regime is the culprit, and as it expands, it continues to undermine the relatively greater sustainability of "developing” countries. Humanity is not predestined to destroy the web of life; we simply have made a wrong turn with the advent of a fossil fuel-driven technology of industrial mass production.

Industrialization had its own techno-utopian allure and briefly held the promise of presumably "higher” living standards for middle-class consumers in some parts of the world. Devastating costs were shifted to the "far end" of an ever-expanding social, geopolitical, and ecological "periphery.” This periphery is now encroaching upon the "near-end” for almost everyone. Exponentially rising inequality (Piketty 2013) and environmental destruction (Ebtekar 
et al. 2015) are now well documented, however, and critiques of an ultimately self-destructive capitalist industrial regime are becoming louder even among its most privileged insiders (Gensler 2017). Indeed, industrialization met with cultural resistance from the start, first, perhaps, by the eighteenth-century Romantic movement. All such resistance has proven futile to date, however, for one simple reason: The industrial regime maintains a powerful ideological defense by portraying this particular system and all its artifacts, including a highly unsustainable variant of human ecology, as a natural, stable condition that is without alternative (see Piketty 2019; Roex, Huijts, and Sieben 2019). While such legitimizing narratives still stand, there is no chance of averting a climate disaster. As we shall see, however, anthropologists are in an excellent position to debunk such claims.

\section{Debunking the pseudo-realism of the robber barons: Toward a "moral ecology" model}

Two different perspectives on human nature and evolution inform the great ideological war of the early twenty-first century. From an ecological perspective, conflict avoidance through differentiation and mutual interdependence is the typical case and a prerequisite for complex systems. From a particularistic perspective, however, conflicts of interest between constituent elements routinely arise both in social and ecosystems. Fatalist realism tends to emphasize such conflicts and uphold "free” competition as a natural law: Life is brutish and human nature selfish—we are "wolves” unto one another. This philosophy struggles to explain, however, why systems have durability, and it denies the force of interdependence (Flannery 2010). 
Nevertheless, this view of (human) nature has become the cultural core narrative legitimizing the status quo of hyperliberal economic regimes, all the way to the edge of extinction. It has served to justify the imperial domination of "weaker" nations, the colonization of diversified production and markets by cartels, and the economic domination of “weaker” individuals (Gould 1981).

This narrative is marketed as consistent with evolutionary science and hence as a form of realism, but this is incorrect. Gause's law (Gause 1934), also known as the competitive exclusion principle, does not mean that the systemic effect of competition in ecosystems is a Hobbesian battle of all-against-all (bellum omnium in omnes). ${ }^{2}$ Rather, competition between species with similar traits drives the diversification of species by way of adaptation to ever more specialized ecological niches. In short, the problem of resource scarcity and associated competition may appear as a deadly struggle from a particularistic perspective, but overall, ecosystems strive to maximize the potential for life. This diversification effect is known as competitive niche shift, whereby competing species with similar traits diverge in the direction of greater specialization (Boer 1986). Healthy ecosystems thus over time resolve competition and exploit it as a motor for continuous diversification, with the ultimate outcome of establishing complex webs of interdependence wherein species are mutually sustained. ${ }^{3}$

This trend toward diversification also applies to social systems. Adam Smith, though a free market advocate, was well aware of similar patterns in economics and critical of pseudorealist approaches. The typical case of economic life is described in Smith’s ([1759] 2002) 
Theory of Moral Sentiments, where he characterizes it as a system of interdependence upheld by sympathy for the moral sentiments of others. Smith ([1776] 1977) then uses the "beggar-thyneighbor" policy of mercantilism to exemplify the atypical case, whereby unsustainable, selfserving economic behavior became a temporary system feature because trade was falsely regarded as a zero-sum game. His contention that "comparative advantage” within economic systems resolves conflict resonates strongly with the way diversification resolves competitive conflicts in ecosystem evolution. Nature and economics, it seems, are not brutish at all; both favor cooperation.

The event-focused, short-term logic of economic realism, driven by the voracious profit appetite of financial capital, thus rests on a pseudo-intellectual misreading of Hobbes, Darwin, Smith, and others that largely does away with broader moral (systemic) concerns. When a business engages in systematically unsustainable behavior, maximizing private profit and externalizing socioecological (systemic) costs, this is portrayed not as immoral but as natural and "rational" (in a narrow, instrumental sense). Unfortunately, the more such behavior spreads, albeit temporarily, the more natural it appears to be. Climate change, like other cultural artifacts, is an idea condensed into reality.

Robber baron economics is also far removed from the anthropological norm. Anthropological comparisons of economic regimes across cultures show most economies do have strong moral foundations. Recognizing this empirical fact, the concept of "moral economy" was developed by the historian E. P. Thompson (1993) and popularized in anthropology by 
James Scott $(1976,1985)$. Scott argues that economic needs are "socially experienced as a pattern of moral rights or expectations” and embedded within social and cultural contexts, and hence that economic anthropology, while it "begins in the domain of economics, must end in the study of ... culture and religion” (Scott 1976, 6). This basic insight has been widely acknowledged, even by Scott's critics (Wells 1994, 292). Moral economy theory reminds us that healthy human ecologies mitigate individual risk by regulating economies (resource allocation regimes) based on an ethos of mutual care, cooperation, solidarity, and trust. Moral economies also tend to be ecologically sustainable, based on an at least partial extension of the same cultural ethos of care to nonhuman nature.

Today's cultural world is not the only possible world; the artifacts we create we can also undo. Anthropology offers a metacultural understanding of how culture shapes our relationship to diverse ecosystems—a relationship that may be sustainable or unsustainable (Reuter 2010). While the conscious design of sustainable "moral ecologies" is difficult, like any system change, and while one size will not fit all, anthropological comparison shows that such ecologies are certainly achievable and, indeed, “normal.” Sustainable moral economics won’t spell the end of the world as such but only of one possible human ecology that, in any case, we should be glad to escape from alive.

\section{Notes}


1 Cultural ecology carries a similar meaning to human ecology but is more prone to misunderstanding. Outside anthropology, culture still tends to be understood narrowly, namely, as being concerned with the arts and popular culture.

2 Hobbes himself was not a fatalistic realist. The shortcomings of what he believed to be the "natural condition" were to be remedied with a "social contract" designed for "taming the wolves.” This is conveniently forgotten by the pseudo-realist market fundamentalists, who see no need to remedy greed or regulate competition.

3 Understanding ecology has implications not only for economics, our means of survival, but also for religion, that is, our understanding of humanity's place and purpose within the cosmos. Religions are experiencing an ecological turn today (Reuter 2011, 2015b), as awareness of ecological crisis increases.

\section{References}

Boer, Pieter J., den. 1986. “The Present Status of the Competitive Exclusion Principle.” Trends in Ecology \& Evolution 1(1): 25-28. https://doi.org/10.1016/0169-5347(86)90064-9.

Crutzen, Paul J., and Eugene F. Stoermer. 2000. “The Anthropocene.” International GeosphereBiosphere Programme Newsletter 41(1): 17-18.

Descola, Philippe. 2005. Par-delà nature et culture. Paris: Gallimard.

Ebtekar, Massoumeh, Fahmy Khaled, Maria Neira, and Nina Cromnier. 2015. "Healthy Planet, Healthy People.” Our Planet. United Nations Environmental Program. May. 
https://www.unenvironment.org/resources/report/our-planet-healthy-planet-healthypeople.

Elias, Norbert. 1982. State Formation and Civilization: The Civilizing Process. Vol. 2. Oxford: Blackwell.

Flannery, Tim. 2010. Here on Earth: A Natural History of the Planet. Melbourne: Text Publishing.

Gause, Georgii F. 1934. The Struggle for Existence. Baltimore: Williams \& Wilkins.

Gensler, Lauren. 2017. “Rising Income Inequality Is Throwing the Future of Capitalism into Question, Says World Economic Forum.” Forbes, January 11. http://www.forbes.com/sites/laurengensler/2017/01/11/world-economic-forum-incomeinequality-capitalism/\#274135505dd3.

Global Footprint Network. 2011. “Ecological Footprint and Human Development Index, 19802011." http://www.footprintnetwork.org/our-work/sustainable-development/.

Gould, Kenneth A., David N. Pellow, and Allan Schnaiberg. 2004. "Interrogating the Treadmill of Production: Everything You Wanted to Know about the Treadmill but Were Afraid to Ask.” Organization \& Environment 17(3): 296-316. https://doi.org/10.1177/1086026604268747.

Gould, Stephen Jay. 1981. The Mismeasure of Man. New York: W. W. Norton.

Piketty, Thomas. 2013. Le Capital au XXIe siècle. Paris: Éditions du Seuil. 
- 2019. Capital and Ideology. Translated by Arthur Goldhammer. Cambridge, MA: Harvard University Press.

Reuter, Thomas A. 2010. “Anthropological Theory and the Alleviation of Anthropogenic Climate Change: Understanding the Cultural Causes of Systemic Change Resistance.” World Anthropology Network E-Journal 5(1): 5-27. http://www.ramwan.net/documents/05_e_Journal/journal-5/2-reuter.pdf.

—. 2011. "Faith in the Future: Climate Change at the World Parliament of Religions, Melbourne 2009.” The Australian Journal of Anthropology 22(2): 260-65. https://doi.org/10.1111/j.1757-6547.2011.00129.x.

— . 2015b. “The Green Revolution in the World’s Religions: Indonesian Examples in International Comparison.” Religions 6(4): 1217-31. https://doi.org/10.3390/rel6041217.

—. 2015a. "In Response to a Global Environmental Crisis: How Anthropologists Are Contributing toward Sustainability and Conservation.” In Averting a Global Environmental Collapse: The Role of Anthropology and Local Knowledge, edited by Thomas A. Reuter, 1-19. London: Cambridge Scholars.

Roex, Karlijn L. A., Tim Huijts, and Inge Sieben. 2019. “Attitudes towards Income Inequality: 'Winners’ versus ‘Losers’ of the Perceived Meritocracy.” Acta Sociologica 62(1): 47-63. https://doi.org/10.1177/0001699317748340.

Scott, James C. 1976. The Moral Economy of the Peasant: Rebellion and Subsistence in Southeast Asia. New Haven, CT: Yale University Press. 
-1985. Weapons of the Weak: Everyday Forms of Peasant Resistance. New Haven, CT: Yale University Press.

Smith, Adam. (1759) 2002. The Theory of Moral Sentiments. New York: Cambridge University Press. https://doi.org/10.1017/CBO9780511800153.

—. (1776) 1977. An Inquiry into the Nature and Causes of the Wealth of Nations. Chicago: University of Chicago Press.

Thompson, Edward P. 1993. Customs in Common: Studies in Traditional Popular Culture. New York: New Press.

Viveiros de Castro, Eduardo. 2004. "Perspectival Anthropology and the Method of Controlled Equivocation.” Tipití: Journal of the Society for the Anthropology of Lowland South America 2(1). http://digitalcommons.trinity.edu/tipiti/vol2/iss1/1.

Wells, Roger. 1994. “E. P. Thompson, Customs in Common and Moral Economy.” The Journal of Peasant Studies 21(2): 263-307. https://doi.org/10.1080/03066159308438548.

This article is protected by copyright. All rights reserved. 


\section{University Library}

\section{- M M N E R VA A gateway to Melbourne's research publications}

Minerva Access is the Institutional Repository of The University of Melbourne

Author/s:

Reuter, TA

Title:

Climate change as a cultural artifact: Anthropological insights to help avert systemic collapse QUESTION: "What does economic anthropology contribute to the understanding of climate change?"

Date:

2021-01-01

Citation:

Reuter, T. A. (2021). Climate change as a cultural artifact: Anthropological insights to help avert systemic collapse QUESTION: "What does economic anthropology contribute to the understanding of climate change?". ECONOMIC ANTHROPOLOGY, 8 (1), pp.175-179. https://doi.org/10.1002/sea2.12197.

Persistent Link:

http://hdl.handle.net/11343/295900 